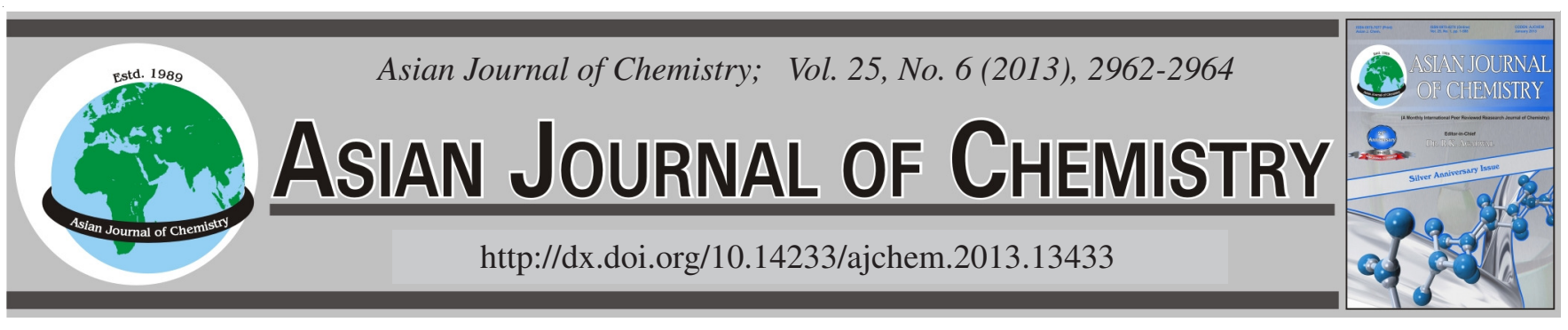

\title{
Physicochemical Characterization and Adsorption Behaviour of Siliceous Soil Towards Aqueous Phosphate
}

\author{
R.K. BEHERA ${ }^{1}$, P.S. DAS ${ }^{1}$ and R. DAS ${ }^{2, *}$
}

${ }^{1}$ Department of Chemistry, North Orissa University, Baripada-757 003, India

${ }^{2}$ Department of Chemistry, M.P.C. (Autonomous) College, Baripada-757 003, India

*Corresponding author: E-mail: dasrita66@ rediffmail.com

(Received: 12 January 2012;

Accepted: 3 December 2012)

AJC-12497

\begin{abstract}
The present study was an attempt to use silica rich soil as an adsorbent for removal of aqueous phosphate. Chemical analyses along with powder XRD, TG-DTA and FT-IR spectra showed silica as the major along with $\mathrm{Ca} / \mathrm{Mg}$ carbonate, iron hydroxide as the minor constituents of the soil. The different of parameters indicated that phosphate adsorption was decreased with increase of $\mathrm{pH}$ and initial phosphate concentrations while increased with increase of adsorbent dose. The maximum monolayer adsorption capacity, derived from fitting of adsorption data to Langmuir isotherm, was found to be $17.95 \mathrm{mg} \mathrm{P} / \mathrm{L}$.
\end{abstract}

Key Words: Natural adsorbent, Phosphate, Siliceous soil, Adsorption kinetics, Adsorption isotherms.

\section{INTRODUCTION}

Extensive research efforts have been devoted in order to reduce anthropogenic input of phosphate into aquatic systems. Chemical precipitation, adsorption/ion exchange and biological methods are some common approaches that have been successfully employed for removal of excess phosphate from contaminated water ${ }^{1}$. Adsorption is by far most versatile and extensively studied method for removal of phosphate from its aqueous solu$\operatorname{tion}^{2-5}$. This method, if combined with appropriate regeneration steps, can solve the problem associated with sludge/secondary waste disposal. In recent years emphasizes are being paid to the use low cost natural adsorbents ${ }^{6-9}$ or industrial wastes ${ }^{10-14}$ to make this method acceptable and economically feasible. Keeping this in view, the present study aims to characterize and determine the efficiency of a natural soil adsorbent for adsorptive removal of aqueous phosphate under varying conditions.

\section{EXPERIMENTAL}

The soil samples used as adsorbent in the present study were collected as lumps from local site of Baripada 21 ${ }^{\circ} 56^{\prime} \mathrm{N}$ $86^{\circ} 43^{\prime}$, Mayurbhanj, Orissa. The samples were air dried for several days, grounded to powder, sieved and $c a .150+200$ $\mu \mathrm{M}$ fraction was taken for further study. Based on the analysis of iron content and preliminary adsorption capacity towards phosphate under identical conditions, a specific sample was selected for further characterization and used for adsorption of aqueous phosphate under varying experimental parameters. The selected sample is fairly white and hereafter referred as
SS. Stock solution of phosphate (1000 mg P/L) was prepared by dissolving $\mathrm{KH}_{2} \mathrm{PO}_{4}$ in distilled water. Working solutions were prepared by suitable dilution of stock solution with distilled water as and when required for different experiments. All other chemicals and reagents used were of analytical grade.

Chemical analyses of the soil samples were carried out by standard wet chemical methods and AAS (Avanta, GBC). A weighed amount of soil was digested in $\mathrm{HCl}-\mathrm{HNO}_{3}$ mixture (3:1) to bring the soluble components in solution and heated to dryness to dehydrate the silica. The whole content was redissolved in $20 \mathrm{~mL} \mathrm{1:1} \mathrm{HCl}$ and filtered. The filtrate along with the washings was used for analyses of major and minor components while silica was estimated gravimetrically from the residue. The crystalline phases present in SS was determined from XRD pattern recorded on a Rigaku (Miniflex II) $\mathrm{X}$-ray diffractometer at scanning speed $2^{\circ} \mathrm{min}^{-1}$ using Ni-filtered $\mathrm{CuK}_{\alpha}$ radiation $(30 \mathrm{kV}, 15 \mathrm{~mA})$. Thermogravimetric measurements (TG-DTA) were performed on a Shimadzu DTG 60 thermal analyzer under flowing nitrogen $\left(40 \mathrm{~mL} \mathrm{~min}^{-1}\right)$ at a heating rate of $10{ }^{\circ} \mathrm{C} \mathrm{min}^{-1}$. FT-IR spectra in $\mathrm{KBr}$ phase was recorded on a Shimadzu IR Affinity 1 spectrophotometer averaging 45 scans with a nominal resolution of $4 \mathrm{~cm}^{-1}$ to improve signal to noise ratio. The point of zero change $\left(\mathrm{pH}_{\mathrm{ZPC}}\right)$ of SS used for the adsorption experiment was determined by batch acid-base titration method as described earlier ${ }^{15}$. In order to confirm the presence of carbonate, the raw soil sample was calcined at the $500{ }^{\circ} \mathrm{C}$ in air for $2 \mathrm{~h}$ using a programmable temperature controller and characterized by XRD and FT-IR. 
Adsorption studies: The adsorption of aqueous phosphate was carried out by batch equilibrium technique at $27 \pm 0.5^{\circ} \mathrm{C}$. A fixed volume $(50 \mathrm{~mL})$ of solution with varying phosphate concentrations in $100 \mathrm{~mL}$ stoppered conical flask, adjusted to desired $\mathrm{pH}$ with diluted $\mathrm{NaOH}$ and $\mathrm{HCl}$ solutions, was treated with different doses of adsorbent (SS) and mechanically shaken in a water bath shaker with a constant stoke $(75 \mathrm{rpm})$ for a pre-determined time. A certain volume of adsorbate was withdrawn at regular time intervals was centrifuged and the phosphate concentration in the supernatant was determined spectrophotometrically by standard phosphovanadomolybdate method $^{14}$. The amount of phosphate adsorbed was determined from the ratio of phosphate in the solution and particulate phases using the following equation.

$$
\mathrm{q}_{\mathrm{e}}=\left(\mathrm{C}_{\mathrm{i}}-\mathrm{C}_{\mathrm{e}}\right) \mathrm{V} / \mathrm{m}
$$

where $\mathrm{q}_{\mathrm{e}}, \mathrm{C}_{\mathrm{i}}, \mathrm{C}_{\mathrm{e}}, \mathrm{V}$ and $\mathrm{m}$ represent the amount of $\mathrm{P}$ adsorbed on the solid $(\mathrm{mgP} / \mathrm{g})$, the initial concentration $(\mathrm{mg} / \mathrm{L})$, the final concentration $(\mathrm{mg} / \mathrm{L})$, volume of the solution $(\mathrm{L})$ and amount of adsorbent $(\mathrm{g})$, respectively.

\section{RESULTS AND DISCUSSION}

Characterization of adsorbent: The chemical analyses reveal that silica, $\mathrm{SiO}_{2}(77.35 \mathrm{wt}$. \%) is the major constituents along with $\mathrm{Mg}$ (4.03), $\mathrm{Ca}$ (2.51) and $\mathrm{Fe}$ (0.64 wt. \%). The air dried soil sample exhibits relatively low weight loss (ca. $4.4 \%$ ) on ignition at $900{ }^{\circ} \mathrm{C}$ indicating the selected sample contains relatively low $\mathrm{H}_{2} \mathrm{O}$ as water of hydration and/or carbonate contents. This weight loss agrees well with that obtained from thermogravimetric analysis (4.26 wt. \%) in which the major weight loss is taken place in between temperature $525-560^{\circ} \mathrm{C}$ with an endothermic peak centred at $512{ }^{\circ} \mathrm{C}$ mainly due to loss of carbonate (Fig. 1, inset). The presence of carbonate is also evident from the qualitative test for carbonate with dil. $\mathrm{HCl}$ releasing $\mathrm{CO}_{2}$.

The XRD pattern of air dried selected sample (Fig. 1) shows mostly the characteristic peaks primarily due to silica (quartz, $\alpha-\mathrm{SiO}_{2}$ ). The peaks of for $\mathrm{CaCO}_{3}$ and $\mathrm{MgCO}_{3}$ are either not observable due to low intensity or merged along

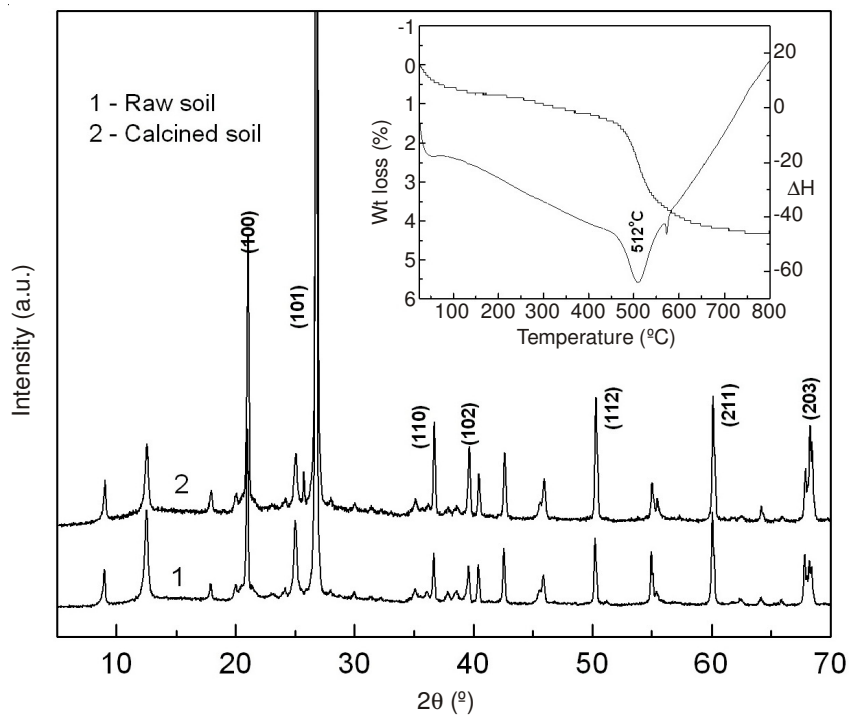

Fig. 1. X-ray diffraction pattern of air-dried and calcined selected sample. (inset) TG-DTA of selected sample with high intensity silica peaks. On calcination, there is practically no change the peak positions except the intensities of peaks are slightly increased. The FT-IR spectra (Fig. 2) shows relatively low intensity broad absorption peaks $c a .3450 \mathrm{~cm}^{-1}$ and moderately intense band at $c a .1641 \mathrm{~cm}^{-1}$ are attributed to $\mathrm{O}-\mathrm{H}$ stretching and bending modes of vibrations, respectively ${ }^{15}$. The low intensity band at $-3450 \mathrm{~cm}^{-1}$ further indicates the presence of low water content in SS. It may be noted that the observable characteristic peak at $1384 \mathrm{~cm}^{-1}$, due to asymmetric stretching of carbonate in air-dried selected sample, is completely disappeared on calcinations at $500{ }^{\circ} \mathrm{C}$ indicating further the presence of carbonate. The absorption peaks at below 1100 $\mathrm{cm}^{-1}$ are mainly attributed to $\mathrm{Si}-\mathrm{O}$ and superimposed carbonate. The position of these peaks is, however, remains practically same on calcination. The $\mathrm{pH}_{\mathrm{ZPC}}$ of selected sample is found to be 3.12 which is slightly higher than the value of pure $\mathrm{SiO}_{2}$ presumably due to presence of $\mathrm{Ca}$ and $\mathrm{Mg}$ carbonates.

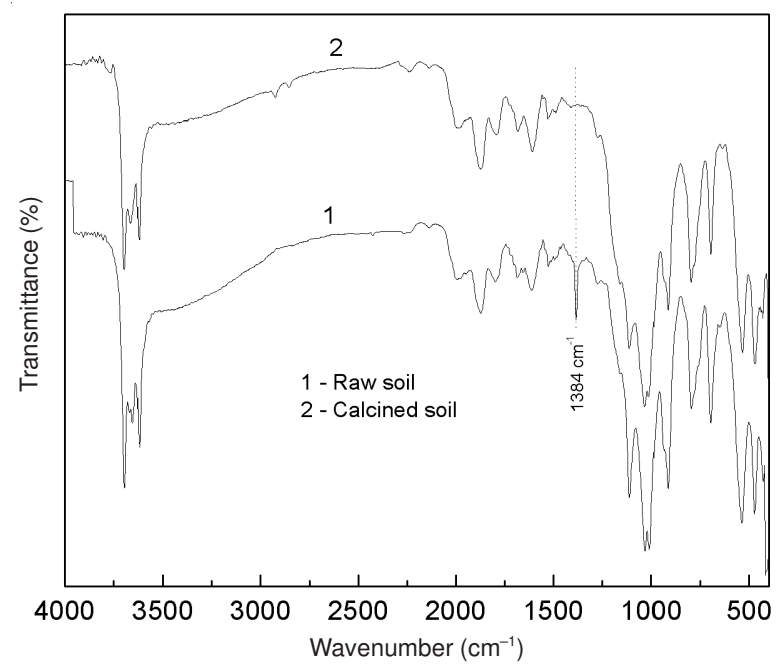

Fig. 2. FT-IR spectra of air-dried and calcined selected sample

Adsorption of phosphate: Preliminary studies with varying initial phosphate concentrations (10-100 mg P/L) at fixed $\mathrm{pH}$ ca. 5.0 and adsorbent dose $(1.0 \mathrm{~g} / \mathrm{L})$ shows that the adsorption process is relatively fast and the equilibrium is attained within $0.5 \mathrm{~h}$. No further change in equilibrium concentration was seen up to $3 \mathrm{~h}$. The time required to reach the equilibrium also appears to be independent of initial phosphate concentration. Hence the equilibrium time is kept $1 \mathrm{~h}$ for all further adsorption experiments.

The effect of $\mathrm{pH}$ on adsorption of phosphate onto selected sample was examined in the $\mathrm{pH}$ region between 3 and 10 and the results obtained are presented Fig. 3. Depending on the $\mathrm{pH}$ of the adsorbing medium, phosphate exit in different ionic forms; $\mathrm{H}_{2} \mathrm{PO}_{4}{ }^{-}$is most abundant below $\mathrm{pH}$ 7.2, while $\mathrm{HPO}_{4}{ }^{2-}$ is prevalent in between $\mathrm{pH} 7.2$ and $12^{14}$. As the $\mathrm{pH}$ of the adsorbing medium decreases below $\mathrm{pH}_{\mathrm{zpc}}$ (3.12), the surface of selected sample become more positive which in turn increase the electrostatic interaction between $\mathrm{H}_{2} \mathrm{PO}_{4}{ }^{-}$and selected sample surface. As a result the percentage of phosphate adsorption increases. Further increase in $\mathrm{pH}$ above $\mathrm{pH}_{\mathrm{zpc}}$, the surface of SS become negatively charged which leads to sharp decrease in adsorption of phosphate as $\mathrm{H}_{2} \mathrm{PO}_{4}{ }^{-} / \mathrm{HPO}_{4}{ }^{2-}$. This suggests the adsorption is mostly based on the electrostatic 


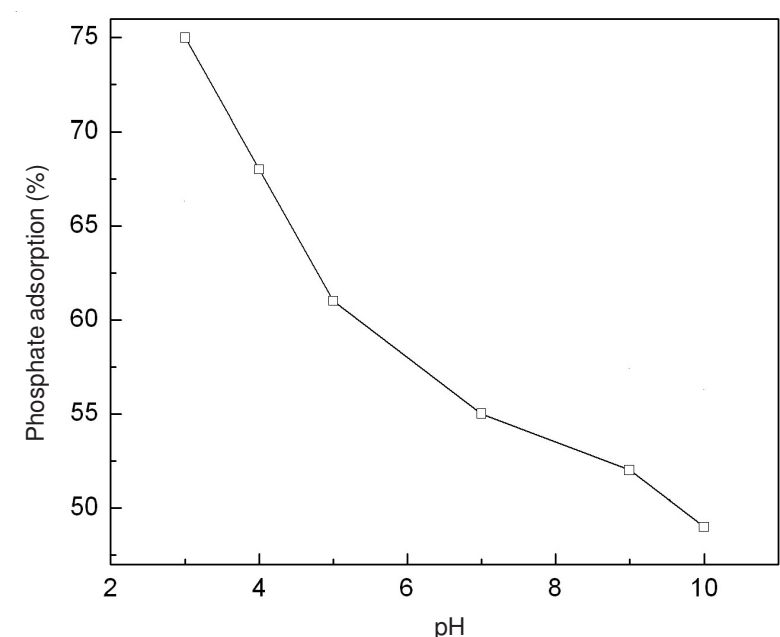

Fig. 3. Effect of $\mathrm{pH}$ on adsorption of phosphate by selected sample with $20 \mathrm{mg} \mathrm{P} / \mathrm{L}$ and adsorbent dose of $1 \mathrm{~g} / \mathrm{L}$

interaction between the negatively charged phosphate and selected sample.

In order to see the effect of adsorbent dose, the amount of selected sample was varied from 0.4 to $2.0 \mathrm{~g} / \mathrm{L}$, keeping the phosphate concentration ( $20 \mathrm{mg} \mathrm{P} / \mathrm{L})$ and $\mathrm{pH}$ (ca. 5.0) fixed. The phosphate adsorption progressively increases from 28.5 to $85.2 \%$ with increase of adsorbent dose from 0.4 to $2.0 \mathrm{~g} / \mathrm{L}$ and as expected there is a decrease of phosphate uptake from 14.25 to $8.52 \mathrm{mgP} / \mathrm{g}$. This decrease may be partly due to nonavailability of enough phosphate concentration for adsorption on SS surface at higher adsorbent doses which in turn decrease the amount of phosphate uptake. On the other hand, the percentage adsorption of phosphate decreases (from 75 to $17.2 \%$ ) with increase of initial phosphate concentration (10 to 100 $\mathrm{mg} \mathrm{P} / \mathrm{L}$ ) and as expected there is an increase phosphate uptake from 7.5 to $17.2 \mathrm{mg} \mathrm{P/g}$ (Fig. 4). The higher uptake with increase of adsorbate concentration is obviously due to availability of enough phosphate ions for adsorption on a fixed number of adsorption sites. A comparison phosphate uptake with other adsorbents reveals that the maximum uptake is comparable with fly ash (2.49 and $8.20 \mathrm{mg}$ P/L for raw and activated at $700{ }^{\circ} \mathrm{C}$ fly ash $)^{12}$ but lower than dolomite (46-47.5 $\mathrm{mg} \mathrm{P} / \mathrm{L})^{6}$ further indicating the potential of selected sample for its possible use as adsorbent for removal of phosphate from wastewaters.

The Langmuir and Freundlich models are the simplest and most commonly used isotherms to represent the adsorption of component from liquid phase onto a solid phase. Fitting of adsorption data, obtained in the above concentration range, to the linearized forms of Langmuir (eqn. 2) and Freundlich (eqn. 3) equations shows a relatively better fitting to Langmuir equation $\left(\mathrm{R}^{2}>0.99\right)$ compare to Freundlich $\left(\mathrm{R}^{2}\right.$ ca. 0.91$)$ equation.

$$
\mathrm{C}_{\mathrm{e}} / \mathrm{q}_{\mathrm{e}}=1 / \mathrm{bQ}_{0}+\mathrm{C}_{\mathrm{e}} / \mathrm{Q}_{0}
$$

where, $\mathrm{C}_{\mathrm{e}}$ is the equilibrium adsorbate concentration in solution, $\mathrm{Q}_{0}$ is the maximum adsorption capacity, $\mathrm{q}_{\mathrm{e}}$ is the amount adsorbed per unit mass of adsorbent and $b$ is the binding energy constant.

$$
\log (\mathrm{x} / \mathrm{m})=1 / \mathrm{n}\left(\log \mathrm{C}_{\mathrm{eq}}\right)+\log \mathrm{K}
$$

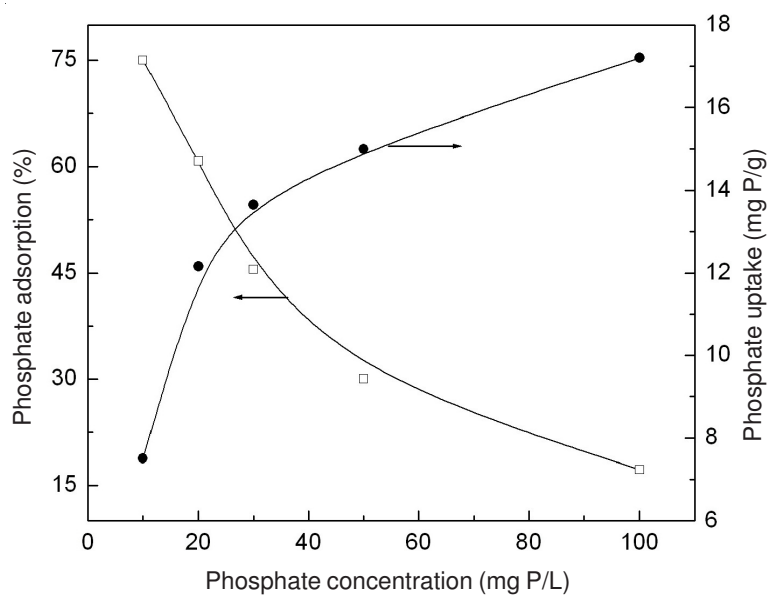

Fig. 4. Effect of initial concentration on phosphate adsorption by selected sample at $\mathrm{pH} 5.0$ and adsorbent dose $1 \mathrm{~g} / \mathrm{L}$

where $\mathrm{K}$ and $1 / \mathrm{n}$ are constants and considered to be relative indicators of adsorption capacity and adsorption intensity, respectively. The maximum adsorption capacity $\left(\mathrm{Q}_{0}\right)$, derived from from Langmuir equation, is found to be $19.95 \mathrm{mg} \mathrm{P} / \mathrm{g}$ which is good agreement with experimental value $(17.2 \mathrm{mg}$ $\mathrm{P} / \mathrm{L})$.

\section{Conclusion}

The present study showed a locally collected silica rich soil was effective for adsorption of phosphate especially at lower $\mathrm{pH}$. The adsorption data was better fitted to Langmuir isotherm yielding a maximum adsorption capacity of 19.95 $\mathrm{mg} \mathrm{P} / \mathrm{g}$.

\section{ACKNOWLEDGEMENTS}

The authors thank Prof. N.N. Das, Department of Chemistry, North Orissa University for helpful discussion.

\section{REFERENCES}

1. E.W. Shin, J.S. Hand, M. Janng, S.H. Min, J.W. Park and R.M. Rowell, Environ. Sci. Technol., 38, 912 (2004).

2. S. Mustafa, M.I. Zaman and S. Khan, J. Colloid Interf. Sci., 301, 370 (2006).

3. Y. Seida and Y. Nakano, Water Res., 36, 1306 (2002).

4. H. He, H. Kang, S. Ma, Y. Bai and X. Yang, J. Colloid Interf. Sci., 343, 225 (2010).

5. B. Grzmil and J. Wronkowski, Desalination, 189, 261 (2006).

6. S. Karaca, A. Gurses, M. Ejder and M. Acikyildiz, J. Hazard. Mater., B128, 273 (2006).

7. K. Karageorgiou, M. Paschalis and G.N. Anastassakis, J. Hazard. Mater., A139, 447 (2007)

8. M. Ozacar, Chemosphere, 52, 321 (2003).

9. L. Zhu and R. Zhu, Sep. Purif. Technol., 54, 71 (2007).

10. G. Akay, B. Keskinler, A.C. Akici and U. Danis, Water Res., 32, 717 (1998).

11. N.M. Agyei, C.A. Strydom and J.H. Potgieter, Cement Concrete Res., 30, 823 (2000)

12. Y. Li, C. Liu, Z. Luan, X. Peng, C. Zhua, Z. Chena, Z. Zhang, J. Fan and Z. Ji, J. Hazard. Mater., B137, 374 (2006) and references therein.

13. E. Oguz, J. Hazard. Mater, B114, 131 (2004) and reference therein.

14. R.K. Behera, P.K. Satapathy, N.S. Randhawa and N.N. Das, Adsorp. Sci, Technol., 28, 411 (2010) and references therein.

15. N.N. Das, P. Pattanaik and R. Das, J. Colloid Interf. Sci., 292, 1 (2005). 